\title{
Application of Sampling Technique to Teacher-Student Ratio in Post Primary Schools of Adamawa State, Nigeria
}

\author{
Adana'a Felix Chama \\ Department of Mathematical Sciences, Taraba State University, Jalingo, Nigeria \\ Email address: \\ chamaadanaa@gmail.com \\ To cite this article: \\ Adana'a Felix Chama. Application of Sampling Technique to Teacher-Student Ratio in Post Primary Schools of Adamawa State, Nigeria. \\ Mathematical Modelling and Applications. Vol. 5, No. 1, 2020, pp. 8-15. doi: 10.11648/j.mma.20200501.12
}

Received: June 20, 2019; Accepted: January 2, 2020; Published: January 17, 2020

\begin{abstract}
National and state-level policies recognize the critical role that teachers play in ensuring that all students learn and building capacity for instrumental excellence in schools. Teachers influence students learning more than any other factor in the school and the dividends of effective teaching quality. In Adamawa state, there is unequal distribution of teachers to public schools which made parents prefer sending their children to private schools rather than the public schools. The study attempts to examines the uniformity of teachers distribution into various educational zones and local governments across the state and also attempt to solve these by applying sampling techniques to allocate and distribute teachers to educational zones and local government of the state. Ratio estimate method was employed to estimate the students' population and compute the students-teacher ratio. The study found unequal distribution for teachers among the urban and rural areas and slight high teachers-students ratio compare to standard of the UNESCO, which is 1:30. To these reasons, the work recommend the application of sampling technique to the management of Adamawa state post primary school management board, Yola for posting and allocation of teachers, and encourage the state government to shift developments to rural areas of the state in order to discourage migration of teachers to urban centers for search of social amenities.
\end{abstract}

Keywords: Variance, Ratio, Estimate, Allocation

\section{Introduction}

Student-teacher ratio is the number of students who attend school in the population study divide by the number of teachers in the school. For instance, a student-teacher ratio of 20:1 indicates that there is one teacher available for every 20 students. The term can also be reverse as a teacher-student ratio means that there are 20 students for every one teacher, which can be written as 1:20.

Smaller classes are widely believed in the developed countries to perform better than the large classes [3]. Students in large classes drift off task because of too much instruction from the teacher to the whole class instead of individual attention. The benefit of smaller class size that is low teacher-student ratio increases the student performance [3]. On the other hand, high teacher-student ratio is often cited for criticizing proportionality, underfunded school or schools system, or as evidence of need for legislative change or more funding of education sector as in the case for Nigerians call for more funding of the education sector. In most of the developed countries, like United States and United Kingdom, where some states and territory have enacted legislation mandating a maximum teacher-student ratio, like Kindergarten in United States. When such figures are stated for schools, they often represent average (mean) and thus are vulnerable to skewing. For example, figures may be biased as follows: if one class has a teacher-student ratio of 1:30 and another has teacher-student ratio of 1:10, the school could claim to have 1:20 teacher-student ratio over all. In school, such ratio are indicative of possible staff changes, if the teacher-student ratio is $1: 50$, the school will probability consider hiring a few teachers. If the teacher-student ratio is very low, classes could be merged and teachers are being fired for redundancy. In extreme cases, the school may close, due to apparent redundancy. Classes with too many students are often disrupting to education. Also, too many students in a class results in a diverse field of students with varying degrees of learning ability [3]. Consequently, the class will spend time for less academics to assimilate the information, when that time could be better spending progressing through the 
curriculum. In this way, teacher-student ratio is compelling arguments for advance or honors classes.

In Adamawa state, a low teacher-student ratio is often used as a selling point and achievement in quality of education expected from the school. The problem contribute to changing schools from one to another by students and even at last finds way to the private school that has low teacher-student ratio. This problem leads to the inability of the State Post Primary School Management Board (PPSMB) to get the actual number of students in the state's public schools to use for planning and administration.

The estimate of student population provides a base for good planning such as provision of basic facilities, proper feeding, good shelters, job opportunity etc.

\subsection{Significance of the Study}

The importance of this study, will give insight of the application of sampling technique to decision making, planning and administration in the educational sector of the economy.

The study will, also serve as an algorithm to the Post Primary School Management Board, Yola, in making use of ratio estimate and Neyman allocation of Staff to various educational Zones (strata) and schools in the state, in order to minimize the routine transfer of staff from one school to another which normally contributes to imbalance in the workforce. The use of estimate of students' population will also minimize the huge amount of money being spent on inventory collection of students' population for ratio estimate.

\subsection{Objectives of the Study}

The study is aimed at applying sampling technique to teacher-student ratio in Adamawa State public Secondary Schools with a view to achieving the following objectives, to

i. Estimate teacher-student ratio in Adamawa state public secondary schools,

ii. Compare the estimated teacher-student ratio of Adamawa secondary school with the recommended teacher-student ratio and,

iii. Suggest the best way of allocation and distribution of teaching staffs to schools and education zones of Adamawa State.

\subsection{Scope and Limitation of the Study}

The scope of the study covered all Adamawa state public secondary schools, grouped into five education zones which served as strata in the study, namely: Mubi Zone, Gombi Zone, Yola Zone, Ganye Zone and Numan Zone.

Due to financial constraints, variability in the geographical zones in Nigeria and variability in the administration of states by individual administrators, coupled with varying degree of literacy, the study was limited to Adamawa State public secondary schools.

\section{Research Methodology}

Estimation is the process of an estimate, or approximation, which is a value that is usable for some purpose even if input data may be incomplete, uncertain or unstable. The value is nonetheless usable because it is derived from the best information available. Typically, estimation involves using the value of a statistic derived from a sample to estimate the value of a corresponding population parameter [5]. In survey that contains a large number of items, there is a great advantage of using estimation procedures that requires little more than simple division and additions. Estimation in statistics involves two dimensional applications. Firstly, the estimation in theoretical statistics such as maximum likelihood,. moments, least square etc. this type of estimation assumes that the researcher knows the functional form of the frequency distribution followed by the data in the sample and the method of the estimation will be geared toward the type of the distribution. Secondly, the preference of estimation which will be used in this study is that of survey theory, which make at most, little assumptions about the frequency distribution and leave its specific functional form out of the discussion. This method is a reasonable one, for handling survey in which the type of distribution may change from one item to another and we do not wish to stop and examine all of them before deciding how to make each estimate.

Therefore, estimation technique for this sample survey work will be restricted in scope and two techniques will be employed: ratio estimation and regression estimation.

\subsection{Population and Sample}

The study was carried out on all the six hundred and sixty eight (668) public secondary schools in Adamawa state. A sample of one hundred and forty three (143) was taken from the population drawn by the method of stratified proportional random sampling, and the number of staff and students were taken from each of the selected school.

Table 1. Nnumber of schools selected in each Educational zone (strata).

\begin{tabular}{lll}
\hline Zone & Population & Sample \\
\hline Gombi & 159 & 34 \\
Yola & 109 & 23 \\
Ganye & 103 & 22 \\
Mubi & 159 & 35 \\
Numan & 138 & 29 \\
Total & 668 & 143 \\
\hline
\end{tabular}

\subsection{Data Collection and Procedure}

An inventory method of data collection was implemented, where a self design inventory was filled by selected schools principals from the population of all selected senior secondary schools in Adamawa state by the method of stratified random sampling. The frame of schools in Adamawa state was obtained from Adamawa State Post Primary Schools Management Board, Yola A proportional stratified sampling was used to select from each educational zones of the state and total number of staffs in each of the selected public secondary schools in the state was collected from the management of Post Primary School Management Board, Yola. 


\subsection{Research Design}

The work comprises of two events; with the first part being the estimation of the students' population in all public secondary schools in the State, which was used for ratio estimation of the number of students to a teacher. The second part involves the use of Neyman allocation method to distribute and allocate available staffs of the board to all the five (5) educational zones and Schools respectively. Precisely, the work was broken into these three stages:

i. Estimation of the student population.

ii. Computation of teacher-student ratio.

iii.Allocation of teachers to education zones and schools.

\subsection{Estimation of Student Population}

The ratio estimate method will examine correlation of the number of staff and number of students from each selected school. The population total of number of staff $X$ of $x$ must be known. Then, if there exist a linear relation between the number of staff and the number of students and the line passes through the origin. The ratio estimate of the students population $\mathrm{Y}$, will be

$$
\mathrm{Y}_{\mathrm{R}}=\frac{y}{x} \mathrm{X}=\frac{\bar{y}}{x} \mathrm{X}
$$

Where $\mathrm{y}, \mathrm{x}$ are the sample totals of the $\mathrm{y}_{\mathrm{i}}$ and $\mathrm{x}_{\mathrm{i}}$ respectively.

\subsection{Computation of the Teacher-Student Ratio}

A quality that is to be estimated from simple random sample is the ratio of two variables (students population and teachers population), both of which varying from school to school. In estimating such ratio, a commonly used procedure has been to take the ratio of unbiased estimators of the numerator and denominator of the population ratio as an estimator and such estimator are termed ratio.

Given that $\left(\mathrm{Y}_{1}, \mathrm{X}_{1}\right)\left(\mathrm{Y}_{2}, \mathrm{X}_{2}\right) \ldots\left(\mathrm{Y}_{\mathrm{n}}, \mathrm{X}_{\mathrm{n}}\right)$ are paired observations in each school of the selected sample, where $\mathrm{X}_{\mathrm{i}}$ is the number of staff, $y_{i}$ is the number of students. Then

$$
\begin{gathered}
Y_{T}=\sum_{i=1}^{n} y_{i}, X_{T}=\sum_{i=1}^{n} x_{i}, \bar{Y}=\frac{Y_{T}}{N}, \bar{X}=\frac{X_{T}}{N}, \\
\operatorname{Ratio}(R)=\frac{Y_{T}}{X_{T}}=\frac{N \bar{Y}}{N \bar{X}}=\frac{\bar{Y}}{\bar{X}}
\end{gathered}
$$

Alternatively, suppose the ratio $\frac{Y_{T}}{X_{T}}$ is to be estimated on the basis of the sample selected through simple random sampling, given $\left(y_{1}, x_{2}\right),\left(y_{2}, x_{2}\right) \ldots\left(y_{n}, x_{n}\right)$.

$$
\begin{gathered}
\hat{R}=r=\frac{\hat{Y}_{T}}{\hat{X}_{T}}=\frac{N \bar{y}}{N \bar{x}}=\frac{\bar{y}}{\bar{x}} \\
\bar{y}=\frac{\sum_{i=1}^{n} y_{i}}{n}, \bar{x}=\frac{\sum_{i=1}^{n} x_{i}}{n}, R=\frac{\sum_{i=1}^{n} y_{i}}{\sum_{i=1}^{n} x_{i}}=\frac{Y_{T}}{X_{T}} \\
Y_{T}=R X_{T}=\left(\frac{\bar{y}}{\bar{x}}\right) X_{T}, \text { where } X_{T} \text { is unknown }
\end{gathered}
$$

\subsection{Allocation of Teachers to Zones and Schools}

The allocation of teachers to zones and schools is affected by three factors: i. The total number of each school in each Zone.

ii. The variability of observation within each Zone.

iii. The cost of allocating each staff to zone and school.

A good allocation is one where maximum precision is obtained with minimum cost or in other word, the criteria of allocating staff to zone is to minimize the cost for a given variance, or minimize the variant for a given cost. This involves transfer cost payable to staff. In allocation of staff to zones and schools: proportional allocation and Optimum allocation/ Neymans allocation.

\subsection{Proportioanal Allocation}

According to [5], we make the proportion of each stratum identical to the proportion of the population.

$$
\begin{aligned}
& \text { Let } f=\frac{n}{N}, N_{h}=f N_{h}, N_{h}=n\left(\frac{N_{h}}{N}\right)=n W_{h} \text { Where } \\
& W_{h}=\frac{N_{h}}{N} \text { is the stratum weight, here } F \text { is constant }
\end{aligned}
$$

across zones, but $\mathrm{W}_{\mathrm{h}}$ varies among strata or alternatively we can say that proportional allocation is:

$$
\begin{gathered}
n=\sum_{h} n_{h}=\sum_{h} k N_{h}=k \sum_{h} N_{h}=\sum_{h} k N_{h} \\
=N K \text {, therefore, } K=\frac{n}{N}
\end{gathered}
$$

To allocate staff to Zones,

$$
\begin{gathered}
n_{1}=\left(\frac{n}{N}\right) * N_{1}, n_{2}=\left(\frac{n}{N}\right) * N_{2}, n_{3}=\left(\frac{n}{N}\right) * \\
N_{3}, n_{4}=\left(\frac{n}{N}\right) * N_{4}, n_{5}=\left(\frac{n}{N}\right) * N_{5}
\end{gathered}
$$

The problem involves in this type of allocation is that, if sample size in a zone is low, it may provide unrealistic stratum specific result, also these may need to use weighting to have unbiased estimates.

\subsection{Optimum Allocation/Neyman Allocation}

This allocation method is based on the variance difference among the stratum. Based on the variability of sampling, more variable strata should be sampled more intensely. With optimum allocation, we allocate the number of teachers to each zone so as to minimize one or two criterion. We either minimize the cost of allocating and transporting the staff for a given value of the variance of our estimate or we minimize the variance of an estimator for a given cost of allocating the staff. We assume a cost function of the form:

$\mathrm{C}=\mathrm{C}_{\mathrm{O}}+\sum \mathrm{C}_{\mathrm{h}} \mathrm{n}_{\mathrm{h}}$ where $\mathrm{c}$ is the total cost of allocating staff, $\mathrm{C}_{\mathrm{O}}$ is the fixed cost of transferring staff, $\mathrm{c}_{\mathrm{h}}$ is the cost of disturbance per school in zone h. clearly, the total cost of allocating staff is the sum of fixed cost and the cost of allocating staff to all the zones.

Where $\mathrm{C}_{\mathrm{O}}=\mathrm{C}_{\mathrm{h}} \mathrm{n}_{\mathrm{h}}$, [6]

Under the assumption of the cost function, the optimum allocation that minimizes the total cost for allocating staff that minimize the total cost for a fixed variance of the estimator for 
a fixed total cost is:

$$
N_{h}=n\left(\frac{W_{h} S_{h}}{\sqrt{C_{h}}}\right)
$$

If the cost per unit sample is the same in all the entire zone (if $\mathrm{Ch}=\mathrm{C}$ for all $\mathrm{h}$ ), then the optimum allocation for a fixed total cost is the same a the optimum allocation for a fixed sample size and we have what is called the Neyman allocation.[14].

He suggest that instead $n_{h} \alpha N_{h}$

We take $n_{h} \alpha N_{h} S_{h}$ (ie $n_{h}$ is proportional to size and the variability in it)

$$
\lambda=\frac{n}{\sum N_{h} S_{h}}, n_{h}=\lambda N_{h} S_{h}=\frac{n N_{h} S_{h}}{\sum N_{h} S_{h}}
$$

That is, Neyman suggest that instead of allocating staff in proportion to the size of the zone, we take as indicated above i.e to the size of the zone and school, and the amount of variability in the zone. Because there may be tendency of having a very big zone, but very alike schools and having a very small zone with a high variability among schools within the zone. Therefore, in this case, allocating large number of staff to bigger zones and smaller number of staff to small zones will not solve the problem of allocation.

\subsection{Methodology}

The study was carried out to estimate, distribute and allocate teachers to various educational zones of the state. Data on teachers and students population were gathered from the selected schools using a self designed inventory list from a sample of one hundred and forty three (143) schools out of the six hundred and sixty eight (668) schools in the state. Thirty four (34) schools from Gombi zone, twenty three (23) schools from Yola Zone, twenty nine (29) from Numan Zone, twenty two (22) from Ganye zone and thirty five (35) from Mubi Zone. Ratio Estimate was used to estimate students' population and calculate the ratio of students to teachers and also Neymans allocation method was employed to distribute and allocate teachers to various Zones of the state and to schools respectively. The detailed stated in research design of this study was used and the strategies of the properties of estimates: ratio estimate was adopted to further explain how good our estimates are for use.

\subsection{Conditions for Ratio Estimator to Be "Best Linear Unbiased Estimator (Blue)}

$[5,15]$, Suggested that for a ratio estimates to be called the best among class of estimates the following conditions will hold.

i. The relation between $(\mathrm{y})$ and $(\mathrm{x})$ is a straight line through the origin.

ii. The variance of $y_{i}$; about this line is proportioned to $x_{i}$

A "best linear unbiased estimator" is defined as follows: consider all estimators $\hat{y}$ of $y$ that are linear function of the sample value $\mathrm{y}_{\mathrm{i}}$, that is, that are of the form:

$$
\mathrm{L}_{1} \mathrm{Y}_{1}+\mathrm{L}_{2} \mathrm{Y}_{2}+\ldots . .+\mathrm{L}_{\mathrm{n}} \mathrm{Y}_{\mathrm{n}}
$$

where the L's do not depend on the $Y_{i}$, although they may be fractions of the $X_{\mathrm{i}}$. The choice of $\mathrm{L}$ 's is restricted to those that gave unbiased estimation of $\mathrm{Y}$. The estimator with the smaller variance is called the best linear unbiased estimator (BLUE). Formally, Brewer and Royall assume that the $N$ Population values $\left(\mathrm{y}_{\mathrm{i}}, \mathrm{x}_{\mathrm{i}}\right)$ are random sample from a super population in which

$$
Y_{i}=\beta X_{i}+\varepsilon_{i}
$$

where the $\varepsilon_{\mathrm{i}}$ are independent of the $\mathrm{x}_{\mathrm{i}}$ and $\mathrm{X}_{\mathrm{i}}>\mathrm{o}$. In arrays in which $\mathrm{x}_{\mathrm{i}}$ is fixed, $\varepsilon_{\mathrm{i}}$ has mean o and variance $\lambda \mathrm{x}_{\mathrm{i}}$. The number of staff for each local government, $\mathrm{X}_{\mathrm{i}},(\mathrm{i}=1,2 \ldots \ldots \mathrm{N})$ are known under (11) above, $\mathrm{Y}=\mathrm{Bx}+\Sigma \varepsilon_{\mathrm{i}}$ is a random variable. In defining an unbiased estimate under this model, Brewer and Royall use a concept of unbiasness which differs from that in randomization theory. They regard an estimator $\hat{Y}$ as unbiased if $\mathrm{E}(\hat{\mathrm{Y}})=\mathrm{E}(\mathrm{Y})$ in repeated selections of the finite population and sample under the model. Such an estimator might be called model - unbiased, they now proved under the model (11) above, that the ration estimator:

$$
\hat{\mathrm{Y}}_{R}=\frac{\bar{y}}{x} x
$$

is a best linear unbiased estimator for any sample, random or not random selected solely according to the values of the $\mathrm{x}_{\mathrm{i}}$.

\section{Data Analysis}

This section presents the estimate teacher-students ratio, estimate students' population in Adamawa State public secondary schools and allocate of teachers to educational zones and local government areas of the state, using the Neyman's allocation method. As in almost all studies, a lot depends on the extends to which the variability make up. in other word, much of the reliability and validity of the procedure adopted in this analysis and the results therein are based on the sample obtained through proportional stratified sampling method of schools from each of the local government are of the state grouped into five (5) educational zones which was used as strata. The frame of the schools was obtained from the Adamawa state post primary school

\begin{tabular}{|c|c|c|c|c|c|c|c|c|c|}
\hline \multicolumn{2}{|c|}{ GOMBI ZONE } & \multicolumn{2}{|l|}{ YOLA ZONE } & \multicolumn{2}{|c|}{ NUMAN ZONE } & \multicolumn{2}{|c|}{ GANYE ZONE } & \multicolumn{2}{|l|}{ MUBI ZONE } \\
\hline STUDENTS & TEACHERS & STUDENTS & TEACHERS & STUDENTS & TEACHER & STUDENTS & TEACHERS & STUDENTS & EACHERS \\
\hline (y1) & (x1) & (y2) & $(\mathrm{x} 2)$ & (y3) & (x3) & $(\mathrm{y} 4)$ & (x4) & (y5) & (x5) \\
\hline 13402 & 358 & 7575 & 407 & 2735 & 67 & 6761 & 115 & 6864 & 209 \\
\hline 9106 & 184 & 7075 & 261 & 1969 & 40 & 3204 & 136 & 5415 & 102 \\
\hline 5931 & 148 & 5127 & 266 & 4138 & 124 & 4762 & 98 & 5050 & 111 \\
\hline
\end{tabular}
management board, Yola, an attempt was also made to calculate the variance of the ratio estimate, bias of the ratio estimate and confidence limits of the population total and ratio total.

Table 2. Ratio Estimate of Teacher-Students in Stratified Sampling by Zone. 


\begin{tabular}{|c|c|c|c|c|c|c|c|c|c|}
\hline \multicolumn{2}{|c|}{ GOMBI ZONE } & \multicolumn{2}{|l|}{ YOLA ZONE } & \multicolumn{2}{|c|}{ NUMAN ZONE } & \multicolumn{2}{|c|}{ GANYE ZONE } & \multicolumn{2}{|l|}{ MUBI ZONE } \\
\hline STUDENTS & TEACHERS & STUDENTS & TEACHERS & STUDENTS & TEACHER & STUDENTS & TEACHERS & STUDENTS & EACHERS \\
\hline (y1) & (x1) & $(\mathrm{y} 2)$ & $(\mathrm{x} 2)$ & $(\mathrm{y} 3)$ & $(\mathrm{x} 3)$ & $(\mathrm{y} 4)$ & (x4) & (y5) & $(\times 5)$ \\
\hline 4670 & 176 & & & 7008 & 128 & 2079 & 30 & 6837 & 255 \\
\hline & & & & 4305 & 102 & & & 6644 & 196 \\
\hline $\mathrm{s} 1=3893.03$ & & $\mathrm{~s} 2=293.41$ & & $\mathrm{~s} 3=1928.76$ & & $\mathrm{~s} 4=2030.21$ & & $\mathrm{~s} 5=862.45$ & \\
\hline $\mathrm{n} 1=34$ & & $\mathrm{n} 2=21$ & & $\mathrm{n} 3=29$ & & $\mathrm{n} 4=22$ & & $\mathrm{n} 5=35$ & \\
\hline $\mathrm{N} 1=159$ & & $\mathrm{~N} 2=99$ & & $\mathrm{~N} 3=138$ & & $\mathrm{~N} 4=103$ & & $\mathrm{~N} 5=159$ & \\
\hline$\sum y 1=33109$ & & $\sum y 2=19777$ & & $\sum y 3=20155$ & & $\sum y 4=16806$ & & $\sum y 5=30836$ & \\
\hline$\sum x 1=866$ & & $\sum \times 2=934$ & & $\sum \times 3=461$ & & $\sum x 4=379$ & & $\sum \times 5=873$ & \\
\hline$\overline{\mathrm{y}} 1=8277.25$ & & $\overline{\mathrm{y}} 2=6592.33$ & & $\overline{\mathrm{y}} 3=4031.00$ & & $\overline{\mathrm{y}} 4=4201,50$ & & $\overline{\mathrm{y}} 5=6162.00$ & \\
\hline$\widehat{\mathrm{R}} 1=38.2$ & & $\widehat{\mathrm{R}} 2=21.2$ & & $\widehat{\mathrm{R}} 3=43.7$ & & $\widehat{\mathrm{R}} 4=44.3$ & & $\widehat{\mathrm{R}} 5=35.3$ & \\
\hline
\end{tabular}

$\mathrm{n}=141 \mathrm{~N}=658 \quad \overline{\mathrm{x}}=167.3 \quad \overline{\mathrm{y}}=5746.8 \quad \widehat{\mathrm{R}}=\mathrm{Y} / \mathrm{X} \widehat{\mathrm{R}}=34.4 \widehat{\mathrm{R}}=34$.

Therefore, the ratio estimate of teacher-students in Adamawa State public secondary schools is 1:34, while the ratio estimates for teacher-student in various educational zones: Gombi, Yola, Numan, Ganye and Mubi are 1:26, 1:45, $1: 16,1: 17$ and $1: 25$ respectively.

\subsection{Estimate of the Students Population.}

Given that the ratio of teacher-students in Adamawa State is:

$$
\begin{gathered}
R=\frac{Y_{T}}{X_{T}}, R=34.4 \\
R=\frac{Y_{T}}{X_{T}}, R=34.4, Y_{T}=R * X_{T} \\
=\frac{\bar{y}}{\bar{x}} X_{T}, \text { where } X_{T} \text { is known to be } 13578, \text { then } \\
\bar{y}=\frac{\sum_{i=1}^{n} y_{i}}{n}, \bar{y}=855.9, \bar{x}=\frac{\sum_{i=1}^{n} x_{i}}{n}, \bar{x}=24.9 \\
\text { Then, } \\
\hat{\mathrm{Y}} R=\frac{855.9}{24.9} * 13578=466723 .
\end{gathered}
$$

Therefore, the estimate of student's population in Adamawa State public secondary school is 466723. Therefore the number of teachers required in Adamawa State Public secondary Schools in order to meet the standard ratio of 1:30 is $466723 / 30=15557$.

Then, $15557-13578=1979$. Where available number of teachers is 13,578 , and estimated number of teachers required for standard ratio of 1:30 is 15557 .

\subsection{Allocation of Teachers to Zones and Local Government Areas}

Using the Neyman's, which suggested that $n_{h} \alpha N_{h}$

We take $n_{h} \alpha N_{h} S_{h}$ (i.e. $n_{h}$ is proportional to size and the variability in it)

$$
\begin{gathered}
n=\sum_{h} \lambda N_{h} S_{h}, n_{h}=\lambda \\
\lambda=\frac{n}{\sum N_{h} S_{h}}, n_{h}=\lambda N_{h} S_{h}=\frac{n N_{h} S_{h}}{\sum N_{h} S_{h}} \text { and } N_{h}=\frac{n_{h}}{n} * N
\end{gathered}
$$

Therefore the distributions of teachers to educational zones using the method above are as follows:

\subsubsection{Allocation to Zones}

\begin{tabular}{|c|c|c|c|c|c|c|}
\hline \multirow{2}{*}{ ZONES } & \multirow{2}{*}{$\begin{array}{l}\text { Number of Teachers in Zone } \\
N_{h}\end{array}$} & \multicolumn{3}{|c|}{ Number of Teachers in the Sample } & \multicolumn{2}{|c|}{ Neyman's allocation } \\
\hline & & $\mathbf{n}_{\mathrm{h}}$ & $\mathrm{S}_{\mathrm{h}} \sum_{h} N_{h} S_{h}$ & $\mathbf{N}_{\mathrm{h}} \mathbf{S}_{\mathrm{h}}$ & $\mathbf{n}_{h}$ & $\mathbf{N}_{\mathrm{h}}$ \\
\hline Gombi & 3884 & 866 & 3893.03 & 15120528.52 & 1839 & 7108 \\
\hline Yola & 3029 & 934 & 1293.40 & 3917738.89 & 476 & 1840 \\
\hline Numan & 2210 & 461 & 1928.80 & 4262559.6 & 518 & 2002 \\
\hline Ganye & 1496 & 379 & 2030.20 & 3037194.16 & 369 & 1426 \\
\hline Mubi & 2959 & 873 & 862,50 & 2551989.55 & 311 & 1202 \\
\hline TOTAL & 13578 & 3513 & & 28890010.72 & 3513 & 13578 \\
\hline
\end{tabular}

Using (8) and (10),

$$
n_{h}=\frac{n}{\sum N_{h} S_{h}} \text { and } N_{h}=\frac{n_{h}}{n} * N
$$

Now, for Gombi zone:

$$
n_{h}=\frac{3513 * 3884 * 3893.03}{28890010.92}=1839
$$

and

$$
N_{h}=\frac{1839}{3513} * 13578=7108
$$

Table 3. Neyman Allocation of Teachers to various Educational Zones in Adamawa.

Table 3 above is the computation of Neymans allocation to zone using the present number of teachers as $\mathrm{N}_{\mathrm{h}}$.

W'here $n=$ total number of sampled teachers from all the five zones.

$\mathrm{N}=$ total number of teachers in Adamawa State. $\mathrm{n}_{\mathrm{h}=}$ total number of sampled teachers in zone $\mathrm{h}$.

$\mathrm{N}_{\mathrm{h}}$ total number of teachers in zone $\mathrm{h}$, and.

$\mathrm{s}_{\mathrm{h}}=$ is the standard error.

Neymans allocation $\mathrm{n}_{\mathrm{h}=}$ is the computed Neymans' sample.

Neymans allocation $\mathrm{N}_{\mathrm{h}}$ is the proportion allocation to zone $\mathrm{h}$. 


\subsubsection{Allocations to Lga}

Gombi Zone

By using (8) and (10):

$$
n_{h}=\frac{n N_{h} S_{h}}{\sum_{h} N_{h} S_{h}}
$$

and

$N_{h}=\frac{n_{h}}{n} * n_{h}$, Now, for local governments in Gombi Zone:

Hong: $n_{h}=\frac{866 * 1691 * 480.4}{2125603.3}=331$, and $N_{h}=\frac{331}{866 * 3884}=$ 1485 .

Table 4. Neyman Allocation of Teachers to Schools in Local Governments of Gombi Zone.

\begin{tabular}{|c|c|c|c|c|c|c|}
\hline \multirow{2}{*}{ LGA } & \multirow{2}{*}{$\begin{array}{l}\text { Number of Teachers in LGA } \\
\text { Nh }\end{array}$} & \multicolumn{3}{|c|}{ Number of Teachers in Sample } & \multicolumn{2}{|c|}{ Neyman's allocation } \\
\hline & & Nh & Sh & NhSh & nh & Nh \\
\hline Hong & 1691 & 358 & 480.4 & 812356.4 & 331 & 1485 \\
\hline Gombi & 768 & 184 & 1040.6 & 799180.8 & 326 & 1462 \\
\hline Song & 701 & 148 & 238.1 & 166908.1 & 68 & 305 \\
\hline Girei & 724 & 176 & 479.5 & 347158.0 & 141 & 632 \\
\hline TOTAL & 3884 & 866 & & 2125603.3 & & 3884 \\
\hline
\end{tabular}

This table above is the computation of Neymans allocation to local government in Gombi zone using the present number of teachers as $\mathrm{N}_{\mathrm{h}}$.

Where $n=$ total number of sampled teachers from all the local governments in Gombi zone.

$\mathrm{N}=$ total number of teachers in Gombi Zone.

$\mathrm{n}_{\mathrm{h}}=$ total number of sampled teachers in local government $\mathrm{h}$.

$\mathrm{N}_{\mathrm{h}}=$ total number of teachers in local government $\mathrm{h}$, and.

$\mathrm{s}_{\mathrm{h}}=$ is the standard error.

Neymans allocation $\mathrm{n}_{\mathrm{h}=\text { is }}$ the computed Neymans' sample.

Neymans allocation $\mathrm{N}_{\mathrm{h}}=$ is the proportion allocation to local government $\mathrm{h}$.

\subsection{Variance of the Ratio Estimate}

In a simple random sampling (SRS) of size $n$, if $n$ is large. Then

$$
V(\hat{R})=\frac{1-f}{n}\left[\frac{\sum_{i=1}^{N}\left(y_{i}-R x_{i}\right)}{N-1}\right]^{2} \text { where } f=\frac{n}{N}
$$

where $f=\frac{n}{N}$

$$
f=\frac{141}{658}=0.2143, V(\widehat{R})=\frac{1-0.2143}{141} *-51.5^{2}=14.78
$$

Also equation (18)

$$
\begin{gathered}
V(\hat{R})=\frac{1-f}{n \bar{x}^{2}}\left[\frac{\sum_{i=1}^{N}\left(y_{i}-R x_{i}\right)}{N-1}\right]^{2} \\
\mathrm{~V}(\hat{\mathrm{R}})=0.0005
\end{gathered}
$$

\subsection{Bias of the Ratio Estimate}

The bias of the ratio estimate is computed as follows:

$$
\hat{R}-R=\frac{\bar{y}-R \bar{x}}{\bar{X}}\left(1-\frac{\bar{x}-R \bar{X}}{\bar{X}}\right)
$$

Here, we have

$\bar{x}=\frac{\sum_{i=1}^{n} x_{i}}{n}=24.9, \bar{X}=\frac{\sum_{i=1}^{N} x_{i}}{N}=20.6, \hat{R}-R=-0.15$

\subsection{Confidence Limits of Population Total and Ratio Total}

Given that $\left.\mathrm{Y}: \hat{\mathrm{y}} \mathrm{R} \pm \mathrm{Z} \sqrt{v}_{\mathrm{V}} \overline{\mathrm{y}} \mathrm{R}\right), \mathrm{R}: \mathrm{R} \pm \mathrm{Z} \sqrt{\mathrm{V}}_{\mathrm{v}}(\widehat{\mathrm{R}})$

Using 5\% significance level, we can compute by using (23)

$\left.\hat{\mathrm{y}} \mathrm{R} \pm \mathrm{Z} \sqrt{\mathrm{v}}_{\mathrm{C}} \overline{\mathrm{y}} \mathrm{R}\right), \hat{\mathrm{y}} \mathrm{R} \pm 1.96 \sqrt{ } 14.78,466723 \pm 7.5,466715$, 466731, $R: R \pm Z V_{V}(\widehat{R})$

$34.4 \pm 1.96 * 0.0005,(34,35)$

\subsection{Proportional Distribution and Allocation of Teachers}

The distribution and allocation of teachers to local governments was carried out by method of proportionality. Using $\mathrm{N}_{\mathrm{h}}=\frac{n_{h}}{n}$, from (8)

Where $\mathrm{N}_{\mathrm{h}}$ is the number of staff allocated to local government.

$\mathrm{n}_{\mathrm{h}}$ is the calculated number of teachers allocated to the local

\begin{tabular}{|c|c|c|c|c|}
\hline ZONE & $\overline{\text { LGA }}$ & TEACHERS & ZONE TOTAL & TOTAL \\
\hline \multirow{4}{*}{ GOMBI } & HONG & 2938 & \multirow{4}{*}{7108} & \\
\hline & GOMBI & 1510 & & \\
\hline & SONG & 1215 & & \\
\hline & GIREI & 1445 & & \\
\hline \multirow{5}{*}{ NUMAN } & LAMURDE & 291 & \multirow{5}{*}{2002} & \\
\hline & SHELLENG & 174 & & \\
\hline & GUYUK & 538 & & \\
\hline & DEMSA & 556 & & \\
\hline & NUMAN & 443 & & \\
\hline GANYE & M/BELWA & 433 & 1426 & \\
\hline
\end{tabular}
government. $\mathrm{N}$ is the calculated number of teachers to the zone.

For Hong local government in Gombi Zone

$$
N_{h}=\frac{n_{h}}{n} * N=\frac{358}{866} * 7108=2938
$$

Table 5. Proportional Allocation of Teachers to LGAs by Zones in Adamawa State. 


\begin{tabular}{|c|c|c|c|c|}
\hline ZONE & LGA & TEACHERS & ZONE TOTAL & TOTAL \\
\hline \multirow{8}{*}{ MUBI } & GANYE & 512 & & \\
\hline & JADA & 369 & & \\
\hline & TOUNGO & 112 & & \\
\hline & MUBI NORTH & 288 & & \\
\hline & MUBI SOUTH & 140 & & \\
\hline & MAIHA & 153 & 1202 & \\
\hline & MICHIKA & 351 & & \\
\hline & MADAGALI & 270 & & \\
\hline \multirow{3}{*}{ YOLA } & YOLA NORTH & 802 & & \\
\hline & YOLA SOUTH & 514 & 1840 & 13578 \\
\hline & FUFORE & 524 & & \\
\hline
\end{tabular}

The table above is the allocation of teachers by the method of proportional which allocate the distributed teachers in table 5.

\section{Summary}

The study is an attempt to explore the use of sampling technique in the educational sector of the economy. It made use of sampling technique tools such as ratio estimate, proportional allocation and Neymans' allocation to teacher-students ratio. It revealed the discrepancies in allocation and distributions of teachers between the rural and urban areas putting aside the schools staff requirements.

\section{Conclusion}

From the results, it is clear that Adamawa State public secondary schools did not attain the standard ratio of 1:30 as recommended by the [17]. Therefore, the state with an estimated total population of students to be 466,723 requires about one thousand seven hundred and seventy nine (1779) additional teachers to meet the standard ratio as calculated in section 4.3 .

The result of educational zones ratio shows that there are more teachers in urban areas than the rural areas of the State; this might be as a result of the need for staying in urban centers for pressure of social amenities etc, which violates the proposal of equal education to all as being emphasized by [17]. From the allocation of teachers to local governments areas of the state, it is clearly seen that some local governments areas such as Gombi, Yola-North, Yola-South, Numan, Mayo-Belwa, Mubi-North, Mubi-South and Michika are under staffed due to the movements of students from rural areas to Urban areas searching for quality education or low teacher-students ratio. This is evident as opined by [1] in his publication, "Teachers' Shortages and Surplus in Senior Secondary Schools in Oyo.

\section{Notation}

The suffix h denotes the zone (strata) as i denote the school (unit) within the zone. The following symbols all refer to zone (strata) h.

$\mathrm{N}_{\mathrm{h}}$ Total number of schools.

$\mathrm{n}_{\mathrm{h}}$ number of schools in zone $\mathrm{h}$.

$\mathrm{y}_{\mathrm{hi}}$ number of student obtained in the $\mathrm{i}^{\text {th }}$ schools in zone $\mathrm{h}$.
$\mathrm{W}_{\mathrm{h}}=\frac{N_{h}}{N}$ zone weight.

$\mathrm{F}_{\mathrm{h}}=\frac{n_{h}}{N_{h}}$ sampling fraction the zone $\mathrm{h}$.

$\overline{\mathrm{Y}}_{\mathrm{h}}=\sum_{i=1}^{N h} \frac{Y_{h i}}{N_{h}}$ sample mean.

$\mathrm{S}_{\mathrm{h}}^{2}=\frac{\sum_{i=1}^{N h}\left(y_{h i}-\overline{Y_{h}}\right)^{2}}{N_{h}-1}$ True variance.

\section{References}

[1] Adeyemi, T. O (2011). Teacher's shortages and surplus in senior secondary school in Ondo State, Nigeria: A critical review, American Journal of social and Management sciences: 2 (5) $156-164$.

[2] Akinsola, A. O (2010). Teachers perception on teaching large classes in Nigerian secondary school. Florida journal of Educational Administration and Policy 3 (2), 112-132.

[3] Blatchford, P; Basseth, P; Penolope (2011). Examining the effect of class size on classroom engagement and teacher- pupil interaction. Learning and Interaction 21: 715-730, 122-135.

[4] Bowley, A. L (1926). Measurement of precision attained in sampling. Bulletin international Statistics institute, Amsterdam 22, 1-62.

[5] Brewer, K. W. R (1963). Ratio Estimation in Finite Population: Some Results Deductible from Assumption of an Underlying Stochastic Process. Australian Journal of Statistics 5, 93-105.

[6] Cochran W. G (1977). Sampling Techniques. New Delhi. John Wiley \& Sons.

[7] Chatterjee, S, (1972). A study of optimal allocation in Multivariate stratified survey. Skand akt. 73, 55-57.

[8] Dayal, S (1985). Allocation of sample using values of auxiliary characteristics. Journal of the statistical planning and inference II. 321-685.

[9] Garba, A, (2012). Secondary Education in Nigeria A synthesis of basic student specific concerns from guidance and counseling. Journal of international Cooperation in Education 15: 195-205.

[10] Ghosh S. P, (1958). A note on stratified random sampling with multiple characters. Columbia Statistical Bulletin, 8: 81-89.

[11] Horvitz, D. G and Thompson, D. J (1952). A generalization of sampling without replacement from finite universe, Journal of the American statistical Association. 47: 663-685.

[12] Kent, R. A. (2001). Estimation, Data construction and Data analysis for Survey Research. 157. 
[13] Lankford, H; Loeb, S and Wyckoff, J (2002). Teachers sorting and the plight of Urban schools. A descriptive analyis. Educational evaluation and policy Analysis. 24 (1): 378-62.

[14] Neyman, J (1934). On two different aspect of the representative method: the method of stratified sampling and the method of purposive selection. Journal of the Royal Statistical society. 97: 558-606.

[15] Royall. R. M (1970), Finite Population sampling theory under certain linear regression Models. Biometrika, 57, 377-387.
[16] Susan, P. O (2012), Analysis of internal efficiency in the utilization of human resources in selected secondary schools in Oyo, Nigeria. Journal of emerging trends in educational research and policy studies (JETERAS) 3 (5): 748-752 (ISSN: 2141-6990)

[17] United Nations Education, Scientific and Cultural Organization, (2000). Institute for Statistics: World Education Indicator. 12: $122-129$. 